\title{
Relationships Between Strength, Flexibility and Field Tests of Upper Extremity in Healthy Individuals
}

\section{Să̆hklı Bireylerde Üst Ekstremite Kuvvet, Esneklik ve Saha Testlerinin İlişkileri}

\author{
Meryem Büke, Fatma Ünver, Elif Gür Kabul \\ School of Physical Therapy and Rehabilitation, Pamukkale University, Denizli, Turkey
}

\section{Büke (iD) \\ 0000-0002-5700-9407 \\ F. Ünver (iD \\ 0000-0002-3100-0818 \\ E. G. Kabul (1) \\ 0000-0003-3209-1499}

Geliş Tarihi / Date Received: 17.09.2018

Kabul Tarihi / Date Accepted: 16.10.2018

Yaym Tarihi/Published Online: 10.01.2019

Yazışma Adresi /

Corresponding Author:

Meryem Büke

Pamukkale Üniversitesi, Fizik

Tedavi ve Rehabilitasyon

Yüksekokulu, Denizli, Turkey

E-mail: mbuke@pau.edu.tr

(C2019 Türkiye Spor Hekimleri Derneği. Tüm hakları saklıdır.

\section{ABSTRACT}

Objective: The purpose of this study is to determine the relationship between strength, flexibility, and field tests of upper extremity in healthy individuals.

Materials and Methods: Fifty healthy individuals ( 25 women, 25 men) volunteered in the study. The physical and clinical characteristics of the participants were questioned using an evaluation form. Muscle strength was measured using a hand dynamometer. Flexibility was measured with a tape. The $Y$ balance test (YBT) and medicine ball throwing were used as upper extremity field tests. Pearson and Spearman correlation analyzes were used to determine the relationship between the parameters.

Results: There was a moderate correlation between medicine ball throwing and YBT total scores $(r=0.507, p<0.01)$. It was revealed that strength and flexibility of the upper extremity were related to YBT scores $(p<0.01$ and $p<0.05$, respectively).

Conclusions: For healthy individuals, there are relations between strength, flexibility and field tests. Increased strength and reduced flexibility for the upper extremity increases physical performance and balance.

Keywords: Muscle strength, balance, flexibility

ÖZ

Amaç: Bu çalışmanın amacı, sağlıklı bireylerde üst ekstremite saha testleri ile kuvvet ve esnekliğin ilişkilerini belirlemekti.

Gereç ve Yöntemler: Çalışmaya 50 sağlıklı birey ( 25 kadın, 25 erkek) gönülü olarak katıldı. Katılımcıların fiziksel ve klinik özellikleri, değerlendirme formu ile sorgulandı. Kas kuvvet ölçümü el dinamometresi kullanılarak yapıldı. Esneklik, mezura ile ölçüldü. Üst ekstremite saha testleri için, $Y$ denge testi (YDT) ve sağlık topu fırlatma kullanıldı. Veriler arasındaki ilişkinin belirlenmesi için Pearson ve Spearman korelasyon analizleri kullanıldı.

Bulgular: Sağlık topu fırlatma ve YDT total skorları arasında orta düzey ilişki bulundu $(r=0.507, p<0.01)$. Üst ekstremite için kuvvet ve esneklik ile YDT değerlerinin ilişkili olduğu saptandı (sırasıyla $p<0.01$ ve $p<0.05$ ).

Sonuçlar: Sağlıklı bireylerde kuvvet, esneklik ve saha testleri arasında ilişki vardır. Üst ekstremite kuvvetinin artması ve esnekliğin azalması, fiziksel performansı ve dengeyi arttırmaktadır.

Anahtar Sözcükler: Kas kuvveti, denge, esneklik

Available at: http://journalofsportsmedicine.org and

http://dx.doi.org/10.5152/tjsm.2019.123

Cite this article as: Buke M, Unver F, Kabul EG. Relationships between strength, flexibility, and field tests of upper extremity in healthy individuals. Turk J Sports Med. 2019;54(2):117-23. 


\section{GİRIŞ}

Fiziksel fonksiyonel kapasite, yaşam kalitesinin önemli bir bileşenidir. Spora ve fiziksel aktiviteye katılım öncesi değerlendirme sırasında, yaralanma riskini tanımlamak amaçlı kas iskelet taramasının bir bileşeni olarak dinamik hareket testinin popülaritesi artmaktadır $(1,2)$. Bilinen yaralanma risk faktörleri; antropometrik ölçüm düzeyleri, oyuncu pozisyonu, beceri düzeyi, antrenman süresi, esneklik, asimetri, yaralanma öyküsü ve oyun yüzeyidir (3).

Esneklik, yaralanmaların önlenmesinde ve fonksiyonelliğin sağlanmasında gerekli olan bir bileşendir. Araştırmalar yetersiz esnekliğin alt ekstremite yaralanmalarına neden olduğunu göstermiştir. Dorsifleksiyon esnekliği kadınlarda diz yaralanmalarını önlemekte (4), hamstring esnekliği ise askeri personelde fonksiyonel hareketleri arttırmaktadır (5). Hamstring kısalığını önlenmek için esnekliğinin arttırılması gerektiği bildirilmiştir (6). Buna karşın, üst ekstremite için omuz eksternal rotatörlerinin ve pektoral kasların esneklikleri ile kuvvet ve saha testleri arasındaki ilişkiler değerlendirilmemiştir.

Saha testleri klinik ortamlarda kullanılabilen, pratik ve kolayca uygulanılabilen testlerdir. Üst ekstremite için Y denge test (YDT) ve sağlık topu firlatma testleri bu saha testleri arasinda yer almaktadır (7).

Literatüre bakıldığında üst ekstremite YDT (YDT-ÜE) kullanılarak yapılan çalışmaların az sayıda olduğu gözlemlendi. Bu çalışmalar atletler (8), yüzücüler (9), güreşçiler (10) gibi düzenli spor yapanlarda gerçekleştirilmişti. Sporcularda hareket kısıtlılıklarını ve asimetrileri tanımlamak ve böylece yaralanmayı azaltabilmek için YDTÜE'nin kullanımı önerilmiştir (11).

Sağllk topu firlatma testi de üst ekstremite kas kuvvetinin ölçümünde kullanılan güvenilir ve geçerli bir yöntemdir (12). İzokinetik kuvvet ölçümleriyle korrele olduğu bulunan ve izokinetik dinamometre yerine önerilen sağlık topu, farklı kilolarda kullanılabilmektedir (13). İzokinetik cihaz pahalıdır ve istenilen yere taşınması açısından dezavantajlıdır.

Kuvvet ölçümünde objektif olarak kullanılan cihazlardan biri de el dinamometresidir. Sağlıklı bireylerde omuz ve skapular kasların kuvvet ölçümünde el dinamometresi kullanımının mükemmel güvenilirlikte olduğu bildirilmiștir (14).

Literatürde sağllk topu fırlatma testi ve YDT-ÜE için omuz ve dirsek izometrik kuvveti ilişkisine bakılan çalışmaya rastlanmamıştır. Üst ekstremite kuvveti ve denge ilișkisini değerlendiren sadece bir çalışmaya rastlanmıştır. Borms ve ark. (8), üst ekstremite yaralanma riski yüksek olan baş üstü spor yapan sporcularda üst ekstremite izokinetik kuvveti ve saha testleri ilişkisini değerlendirmişlerdir.

Günümüzde sağlı ve kozmetik nedenlerle rekreatif spora katılımı giderek artmaktadır. Sportif aktiviteler ve günlük yaşam aktiviteleri sırasında sağlıklı bireyler de yaralanabilmektedir. $\mathrm{Bu}$ nedenle çalışmamızda, sağlıklı bireylerde kuvvet, esneklik ve saha testleri arasındaki ilişkilerin belirlenmesi amaçlandı. İkinci amaç ise bu açıdan cinsiyetler arası farkı incelemekti.

\section{GEREÇ ve YÖNTEMLER}

Çalışma Mart-Haziran 2016 tarihleri arasında gerçekleştirildi. Pamukkale Üniversitesi Girişimsel Olmayan Klinik Araştırmalar Etik Kurulundan 60116787-020/16532 karar sayılı izin alındı. Tüm katılımcılara sözel bilgilendirme yapıldı ve bilgilendirilmiş onam formu imzalatıldı. Çalışma Helsinki Bildirgesinde tanımlanan ilkelere uygun yürütüldü. Referans alınan makaleden (8) elde edilmiş korelasyon sonuçlarından yola çıkarak yapılan güç analizi sonucunda çalışmaya en az 28 kişi alındığında $\% 95$ güvenilir ve $\% 90$ güçte sonuç elde edileceği hesaplandı. Olası kayıplar göze alınarak çalışmadaki birey sayısı bu rakamın üstünde tutuldu.

Çalışmaya 18-30 yaş aralığında olan, 50 sağlıklı üniversite öğrencisi (25 kadın, 25 erkek) gönüllü olarak katıldı. Son altı ay içinde üst ekstremiteye ilişkin patolojisi veya yaralanma öyküsü olan, omurgada hipo/hiper lordoz/kifozu bulunan, sempatik sinir sistemi fonksiyonunu değiştirecek herhangi bir destek veya ilaç alan veya iletişim kurulamayan bireyler çalışma dışı tutuldu. 
Araştırmaya başlamadan önce fiziksel ve klinik özellikler değerlendirme formu ile sorgulama yapıldı. Değerlendirme formu kişisel bilgileri ve klinik durumları (yaş, boy, vücut ağırlığı, dominant taraf, son altı aydaki ameliyat ve yaralanma) içermekteydi.

Araştırmacı fizyoterapist gerekli bilgilendirmeyi yaparak ölçümleri gerçekleştirdi. Isınma için koşu bandında $5 \mathrm{dk}$ tempolu yürüyüş egzersizi yapıldı. Esneklik ölçümleri mezura ile yapılıp saha testi için sağlık topu, dinamik denge için Y denge test (YDT) kiti, kuvvet için de el dinamometresi kullanıldı. Ölçüm değerleri form üzerine kaydedildi. Değerlendirmeler, her gün öğleden sonra, aynı fizyoterapist tarafından gerçekleştirildi.

\section{Esneklik Ölçümleri}

Esneklik ölçümleri için kas kısalık testleri bilateral olarak ve üç tekrarlı alındı. Ortalama değerler elde edildikten sonra sağ ve sol toplamı ikiye bölünerek normatif değerler elde edildi.

Pektoral kasların kısalık testi: Birey dizler hafif fleksiyonda olacak şekilde sırtüstü yatırıldı. $\mathrm{Bu}$ pozisyonda eller ensede, lumbal vertebraların düzgünlügü korunarak ve dirsekler zorlanmadan serbest bir şekilde yatak ile temas ettirilmesi istendi. Eğer dirsekler yatağa değmiyorsa, humerusun lateral epikondili ile yer arasındaki mesafe mezura ile ölçüldü (15).

Omuz eksternal rotatörlerinin kısalık testi: Birey oturma pozisyonunda iken, omuzlar $90^{\circ}$ abdüksiyona alındı. Baş parmaklar kalan dört parmakla kapatılıp yumruk yapıldı. Tek bir hamlede sirt üzerine bu iki yumruk yerleștirilip aradaki mesafe mezura ile ölçüldü (15). Bu ölçümde artış esnekliğin azaldığını göstermektedir.

\section{Ekstremite Uzunluk Ölçümleri}

C7-Orta parmak ucu uzunluğu: Mezura kullanılarak iki yönde (sağ-sol) ölçüm yapıldı. Birey ayakta dik pozisyonda iken C7 vertebranın spinöz çıkıntısı ve orta parmağın uç noktası, araştırmacı fizyoterapist tarafından tespit edildi. Tespit sonrası mezurayla aradaki mesafe ölçüldü. Ölçüm sonucu üst ekstremite uzunluğunu vermektedir. $\mathrm{Bu}$ değer $\mathrm{Y}$ denge testinin toplam skorunu belirlemek için kullanıldı (16). YDT için üç yöndeki ortalama değerlerin üst ekstremite uzunluğuna bölünmesi ve çıkan sonucun 100 ile çarpılmasıyla toplam skor hesaplandı (17).

\section{Saha Testleri}

Sağlık topu firlatma testi: Birey oturma pozisyosununda sırtı, omuzları ve başı duvara gelecek șekilde pozisyonlandı. Üst ekstremite $90^{\circ}$ abdüksiyon ve dirsekler fleksiyonda olacak şekilde her iki el arasında 3 kg'lık sağlık topu tutturuldu. Bu pozisyonda sirt, omuzlar ve baş duvar ile teması kaybetmeden sağlı topunun mümkün olduğunca ileri doğru firlatılması istendi (8). Atışlar arasında birer dakikalık dinlenme aralıkları verilerek maksimal çabayla dört atış gerçekleştirildi. Ortalama değerler alındı.

Üst ekstremite $Y$ denge test (YDT-ÜE): Bireylerin fonksiyonel dinamik postüral denge değerlendirmeleri Y denge testi ile yapıldı. Y denge test kiti üzerinde skorlar üç yöne göre kaydedilmektedir. Aralarında $120^{\circ} \mathrm{lik}$ açılar olan medial, süperolateral ve inferolateral yönlerdeki YDT kiti kullanıldı. Test kiti üzerinde test edilen el, açıların birleşim noktasındaki düzeneğin ortasına gelecek şekilde şınav pozisyonunda iken, katılımclardan YDT kutusunu diğer elin parmak ucu ile uzanabildiği en uzak noktaya kadar götürüp eski pozisyonuna geri getirmesi istendi ve uzanabildiği mesafe $\mathrm{cm}$ cinsinden ölçüldü. Ölçümler üç tekrarlı ve bilateral olarak alındı. Ortalama değerler elde edildikten sonra sağ ve sol toplamı ikiye bölünerek normatif değerler elde edildi (1).

\section{Kuvvet Ölçümü}

El dinamometrisi: Commander Powertrack II marka cihaz ile gerçekleşen ölçümlerde el dinamometresi kullanıldı. Çalışmada omuz fleksiyon-abdüksiyonu ve dirsek fleksiyonu ölçümleri için standart bir sandalyede oturma pozisyonu; omuz internal-eksternal rotasyonu ve dirsek ekstansiyonu ölçümleri içinse sırt üstü ve yüzüstü yatış pozisyonları kullanıldı (18).

Ölçümler için katılımcılardan ekstremitelerinin pozisyonlarını tüm güçleriyle korumaları istendi. Ölçümler üç tekrarlı ve bilateral olarak alındı. Ortalama değerler elde edildikten sonra sağ ve 
sol toplamı ikiye bölünerek normatif değerler elde edildi.

\section{İstatistiksel Analiz}

Veriler SPSS 23 paket programıla analiz edildi. Sürekli değişkenler ortalama \pm standart sapma (SD), kategorik değişkenler sayı ve yüzde olarak verildi. Verilerin normal dağılımları incelendikten sonra, sürekli değişkenler arasındaki ilişkiler Spearman ya da Pearson korelasyon analizleri kullanılarak yapıldı. Bağımsız grup farklılıkların karşılaștırılması Mann-Whitney U testiyle yapıldı.

\section{BULGULAR}

Çalışmaya 50 sağlıklı üniversite öğrencisi $(25$ kadın, 25 erkek) dahil edildi. Katılımclların fiziksel verileri Tablo 1'de gösterilmektedir.
Tablo 1. Fiziksel veriler

\begin{tabular}{lcc}
\hline & Kadın $(\mathrm{n}=25)$ & Erkek $(\mathrm{n}=25)$ \\
\hline Yaş $(\mathrm{yıl})$ & $22.4 \pm 1.5$ & $22.6 \pm 1.7$ \\
Boy $(\mathrm{cm})$ & $164.0 \pm 7.5$ & $180.1 \pm 7.0$ \\
Ağırlık $(\mathrm{kg})$ & $57.9 \pm 8.6$ & $75.6 \pm 9.3$ \\
VKİ $\left(\mathrm{kg} / \mathrm{m}^{2}\right)$ & $21.5 \pm 2.6$ & $23.3 \pm 2.8$ \\
\hline
\end{tabular}

Değerler X \pm SD olarak verilmiştir VKİ: vücut kitle indeksi

Üst ekstremite kas kuvveti ile saha testlerinin ilişkisine bakıldığında; kuvvet sonuçları ile YDTÜE skorları arasında pozitif yönlü orta ve yüksek düzeyde ilişkiler elde edilirken, kuvvet ile sağlık topu firlatma sonuçları arasında yüksek ve çok yüksek düzeyde ilişkiler elde edildi $(\mathrm{p}<0.01)$. Kas kuvveti ile kısalığı arasındaki ilişkiler Tablo 2'de özetlenmektedir.

Tablo 2. Üst ekstremite kas kuvvetinin saha testleri ve kısalıkla ilişkisi $(n=50)$

\begin{tabular}{lcccc}
\hline Kuvvet (N) & YDT-ÜE total & Sağlık topu & $\begin{array}{c}\text { Pektoral kas } \\
\text { kisalığ }\end{array}$ & $\begin{array}{c}\text { Eksternal rotatör } \\
\text { kas kısalığ }\end{array}$ \\
\hline Omuz fleksiyon & $0.554^{* *}$ & $0.688^{* *}$ & $0.354^{*}$ & $0.428^{* *}$ \\
Omuz abdüksiyon & $0.611^{* *}$ & $0.738^{* *}$ & $0.409^{* *}$ & $0.403^{* *}$ \\
Omuz internal rotasyon & $0.607^{* *}$ & $0.773^{* *}$ & $0.385^{* *}$ & $0.489^{* *}$ \\
\hline Omuz eksternal rotasyon & $0.501^{* *}$ & $0.629^{* *}$ & $0.500^{* *}$ & $0.434^{* *}$ \\
\hline Dirsek fleksiyon & $0.471^{* *}$ & $0.654^{* *}$ & 0.256 & $0.458^{* *}$ \\
\hline Dirsek ekstansiyon & $0.526^{* *}$ & $0.805^{* *}$ & $0.437^{* *}$ & $0.557^{* *}$ \\
\hline
\end{tabular}

YDT-ÜE: Üst ekstremite Y Denge Test. Değerler korelasyon analizine göre. *: p<0.05, **: p<0.01. r<0.20: çok zayıf iliş̧i, r:0.20-0.39: zayıf ilişki, r: 0.40-0.59: orta ilişki, r: 0.60-0.79: yüksek ilişki, r>0.80: çok yüksek ilişki.

Saha testleri ile eksternal rotatörlerin kısalığına bakıldığında zayıf düzeyde ilişki elde edildi $(\mathrm{p}<0.05)$. YDT-ÜE ile pektoral kasların kısalı̆̆ arasında anlamlı düzeyde ilişki bulunmazken, sağlık topu firlatma ile pektoral kasların kısalığı arasında zayıf düzeyde ilişki elde edildi $(\mathrm{p}<0.01)$ (Tablo 3). Saha testlerinin kendi arasındaki ilişki incelendiğinde, YDT-ÜE total ve sağlık topu firlatma arasında orta düzeyde pozitif yönlü ilişki bulundu ( $\mathrm{r}=0.507, \mathrm{p}<0.01)$.

Tablo 3. Saha testleri ve kısalık ilişkisi

\begin{tabular}{lcc}
\hline Saha testleri & Pektoral kasların kısalığı & Eksternal rotatörlerin kısalığı \\
\hline YDT-ÜE total & 0.264 & $0.306^{*}$ \\
Sağlık topu fırlatma & $0.368^{* *}$ & $0.319^{*}$ \\
\hline YDT-ÜE: Üst ekstremite Y Denge Test. Değerler korelasyon analizine göre. ${ }^{*}: \mathrm{p}<0.05,{ }^{* *}: \mathrm{p}<0.01 . \mathrm{r}<0.20:$ çok \\
zayıf ilişki, r:0.20-0.39: zayıf ilişki, $r: 0.40-0.59:$ orta ilişki, $r: 0.60-0.79:$ yüksek ilişki, $r>0.80:$ çok yüksekilişki.
\end{tabular}


Cinsiyete göre yapılan karşılaştırmada, kuvvet ve saha testlerinin sonuçlarında erkeklerde kadınlardan daha iyi sonuçlar elde edildi $(p<0.001)$. Pektoral kasların esnekliği açısından cinsiyetler arasında fark gözlenmezken, kadınların eksternal rotatörlerindeki kısalık sonuçları erkeklerin değerlerinden daha iyi düzeyde bulundu (Tablo 4).

Tablo 4.Cinsiyete göre seçilen parametrelerin karșılaștırılması

\begin{tabular}{lccc}
\hline & Kadın (n=25) & Erkek (n=25) & p \\
\hline Omuz fleksiyon (N) & $101.7 \pm 18.3$ & $145.2 \pm 31.3$ & $<0.001$ \\
Omuz abdüksiyon (N) & $90.2 \pm 16.3$ & $140.7 \pm 33.5$ & $<0.001$ \\
Omuz internal rotasyon (N) & $51.5 \pm 11.2$ & $84.5 \pm 22.0$ & $<0.001$ \\
Omuz eksternal rotasyon (N) & $53.5 \pm 16.5$ & $82.4 \pm 21.2$ & $<0.001$ \\
Dirsek fleksiyon (N) & $108.4 \pm 19.1$ & $164.5 \pm 48$ & $<0.001$ \\
Dirsek ekstansiyon (N) & $81.1 \pm 16.3$ & $126.8 \pm 27.3$ & $<0.001$ \\
YDT-ÜE total (cm) & $73.1 \pm 5.9$ & $82.7 \pm 8.3$ & $<0.001$ \\
\hline Sağlık topu (cm) & $256 \pm 26$ & $502 \pm 67$ & $<0.001$ \\
Pektoral kasların kısalığı (cm) & $5.56 \pm 1.85$ & $6.58 \pm 1.95$ & $>0.05$ \\
\hline Eksternal rotatörlerin kısalığı (cm) & $13.7 \pm 5.4$ & $19.4 \pm 10.7$ & $<0.05$ \\
\hline
\end{tabular}

Değerler X \pm SD olarak; YDT-ÜE: Üst ekstremite Y denge testi

\section{TARTIŞMA}

Çalışma sonuçlarına göre üst ekstremite için kuvvet, esneklik ve saha testleri arasında ortayüksek düzeyde değişen ilişki bulundu. Üst ekstremite kuvvetinin artması, fiziksel performansı ve dengeyi arttırmaktadır. Omuz çevresi kaslarındaki kısalık artarken, yani omuz çevresinin esnekliği azalırken; kuvvet, denge ve sağlık topu fırlatma skorlarında artış gözlendi.

Literatürde YDT-ÜE'yi değerlendiren çalışmalara bakıldığında; baș üstü spor yapanlar $(8,19)$, beyzbol oyuncuları $(10,20,21)$ güreşçiler $(10)$, yüzücüler $(9,22)$, halterciler $(23)$, sağlıklı ve fiziksel olarak aktif bireyler (16) değerlendirmeye alınmıștır. Bu çalıșmalardan Butler ve ark.'nın çalışmasında (22) total YDT-ÜE skoru kadınlarda $83.4 \pm 8.3$, erkeklerde ise $88.3 \pm 8.9$ bulunurken, Bullock ve ark. (9) bu skoru kadınlarda $101.3 \pm$ 7.2 , erkeklerde ise $105.2 \pm 7.9$ bulmuşlardır. Bizim çalışmamızda ise total YDT-ÜE skoru kadınlarda $73.1 \pm 5.9$, erkeklerde $82.7 \pm 8.3$ bulundu. Fiziksel aktivite durumu arttıkça dinamik denge skoru artmaktadır. Çalışmamıza katılan kişiler ise düzenli egzersiz alışkanlığı bulunmayan sağlıklı bireylerdi. Bu nedenle total
YDT-ÜE skorunun diğer çalışmalardan daha düşük çıkması beklenilen bir sonuçtur.

Çalışmanın sonucunda kadınların erkeklerden daha esnek olduğunu gözlemlendi. Teyhen ve ark. (5) askeri personelin güç, denge, esneklik ve fonksiyonel hareketlerine dair normatif veriler vermişlerdir. Denge için alt ve üst ekstremite YDT'nin kullanıldığı bu çalıșmada bizim çalışmamızda olduğu gibi denge skorlarında erkeklerde daha iyi sonuçlar elde edilmiștir. Üniversiteli yüzücülerde cinsiyet farklılığına bağlı YDT-ÜE'nin değerlendirildiği başka bir çalışmada da erkekler kadınlardan daha yüksek skorlar elde etmişlerdir (22).

Çalışmada omuz ve dirsek kuvvetlerinin dinamik dengeyi sağlamada önemli bir yeri olduğu gözlemlendi. Bizim çalıșmamızla aynı yaş grubunda sporculara yönelik çalışmalarında Borms ve ark. (8) omuz-dirsek izokinetik kuvvet değerleri ile sağlık topu firlatmada ulaşılabilen mesafe arasında güçlü ilişki elde etmişlerdir $(\mathrm{r}=0.595-0.855)$. Buradaki çalışmada da benzer şekilde izometrik kuvvetle güçlü ilişki bulundu $(\mathrm{r}=0.629-0.805)$. Sözü geçen çalışmada izokinetik kuvvet ile YDT-ÜE değişkenleri arasında ilişki 
bulunmazken, burada da el dinamometresi ile yapılan izometrik kuvvet ve YDT-ÜE değişkenleri arasında güçlü ilișki elde edildi ( $\mathrm{r}=0.471-0.611)$. YDT-ÜE performansında üzerinde durulan ekstremitenin stabilitesi ön planda olduğu için çalıșmada izometrik kuvvet ile YDT-ÜE arasında yüksek düzeyde ilişki elde edildiğini düşünmekteyiz.

Literatürdeki çalışmalara bakıldığında sağlık topu firlatma testi için kullanılan top ağırlıkları ve uygulanıș pozisyonunun değișkenlik gösterdiği anlaşılmaktadır. Tilaar ve ark. (13) oturma ve ayakta durma pozisyonunda farklı ağırlıktaki (1, 3 ve $5 \mathrm{~kg}$ ) sağlık toplarının firlatılma hızlarının güvenilirliğini incelemişler; ayakta yapılan firlatma ölçümleri arası fark olduğunu, oturarak gögüs pası şeklinde yapılan ölçümlerin daha güvenilir olduğunu belirtmişlerdir. Harasin ve ark. (24) otururken göğüs pasında daha fazla stabilitenin sağlandığını ve ölçüm sonuçlarının daha az değişkenlik gösterdiğini bildirmişlerdir.

Bu nedenle çalışmamızda da sağlık topu fırlatma için oturur pozisyonda göğüs pası seçildi ve Harasin ve ark.'nın çalışmasındaki gibi 3 kg'llk sağlık topu kullanıldı. Çalışma sonucunda sağlık topu fırlatma mesafesinin kas kısalığının artışı, yani esneklikteki azalma ile arttığ bulundu. Ancak bu ilişkinin oldukça zayıf olduğu gözlendi $(\mathrm{r}=0.319-0.368)$. Kullanılan saha testlerinin kendi aralarındaki ilișki incelendiğinde, YDT-ÜE ile sağlık topu firlatma arasında orta düzeyde pozitif yönde ilişki elde edildi ( $\mathrm{r}=0.507)$. Bu da dinamik dengeleri iyi olan kişilerin patlayıcı gücünün de daha iyi olduğu sonucunu bize vermektedir.

Güç analizinin yapılmış olması, kuvvet ölçümünde el dinamometresi gibi objektif, taşınabilir ve kolay uygulanabilen bir cihazın kullanılması çalışmanın güçlü yanlarıdır. Dengenin sağlanmasında özellikle distal eklemi stabilize eden kaslarda görev aldığı için el bileği kuvveti de değerlendirmeye dahil edilebilirdi. $\mathrm{Bu}$ da çalışmanzın sınırlılığını oluşturmaktadır. Gelecek çalışmalarda, saha testlerinde yaralanma öyküsüne göre fark olup olmadığı incelenerek, bu testlerin prediktif olarak uygulanabilirlikleri araștırılabilir.

\section{SONUÇ}

Çalışma sonucunda sağlıklı bireylerde üst ekstremite kas kuvvetinin, saha testleri ve esneklikle orta-yüksek düzeyde değișen ilișkisi olduğu belirlendi. Sağlıklı bireylerde omuz ve dirsek kas kuvvetinin artışı dinamik dengeyi de arttırmaktadır. Esnekliğin artışı ise kuvvet ve denge sonuçlarını olumsuz yönde etkilemektedir. İzometrik kas kuvvetinin arttırılması üst ekstremitelerde dinamik denge performansını arttırarak bireyin yaralanma riskini daha da azaltabilir. Fiziksel performansı belirlemek için spor salonlarında kullanılan testlere; saha testleri de daha kolay ve dinamik ölçümler olarak eklenebilir; hatta açık kinetik olan testler yerine fiziksel performansı düşük bireylerde kapalı kinetik ve güvenli bir test olarak üst ekstremite YDT'nin kuvvet testleri yerine kullanımı da önerilebilir.

\section{KAYNAKLAR}

1. Plisky PJ, Rauh MJ, Kaminski TW, et al. Star Excursion Balance Test as a predictor of lower extremity injury in high school basketball players. J Orthop Sports Phys Ther. 2006;36(12):911-9.

2. Plisky PJ, Gorman PP, Butler RJ, et al. The reliability of an instrumented device for measuring components of the star excursion balance test. N Am J Sports Phys Ther. 2009;4:92-9.

3. McGuine T. Sports injuries in high school athletes: a review of injury-risk and injury-prevention research. Clin J Sport Med. 2006;16(6):488-99.

4. Malloy P, Morgan A, Meinerz C, et al. The association of dorsiflexion flexibility on knee kinematics and kinetics during a drop vertical jump in healthy female athletes. Knee Surg Sports Traumatol Arthrosc. 2015; 23(12):3550-5.

5. Teyhen DS, Riebel MA, McArthur DR, et al. Normative data and the influence of age and gender on power, balance, flexibility, and functional movement in healthy service members. Mil Med. 2014;179(4):413-20.

6. Yıldırım MŞ, Tuna F, Demirbağ Kabayel D, et al. The cut-off values for the diagnosis of hamstring shortness and related factors? Balkan Med J. 2018;35(5):388-93.

7. Moran J, Wilson F, Guinan E, et al. The preoperative use of field tests of exercise tolerance to predict postoperative outcome in intra-abdominal surgery: a systematic review. J Clin Anesth. 2016;35:446-55.

8. Borms D, Maenhout A, Cools AM. Upper quadrant field tests and isokinetic upper limb strength in overhead athletes. J Athl Train. 2016;51(10):789-96.

9. Bullock GS, Brookreson N, Knab AM, et al. Examining fundamental movement competency and closed-chain 
upper-extremity dynamic balance in swimmers. J Strength Cond Res. 2017;31(6):1544-51.

10. Myers H, Poletti M, Butler RJ. Difference in functional performance on the upper-quarter Y-balance test between high school baseball players and wrestlers. J Sport Rehabil. 2017;26(3):253-9.

11. Gorman PP, Butler RJ, Plisky PJ, et al. Upper quarter Y balance test: reliability and performance comparison between genders in active adults. J Strength Cond Res. 2012;26(11):3043-8.

12. Davis KL, Kang M, Boswell BB, et al. Validity and reliability of the medicine ball throw for kindergarten children. J Strength Cond Res. 2008;22(6):1958-63.

13. Van den Tillaar R, Marques MC. Reliability of seated and standing throwing velocity using differently weighted medicine balls. J Strength Cond Res. 2013;27(5):1234-8.

14. Celik D, Dirican A, Baltaci G. Intrarater reliability of assessing strength of the shoulder and scapular muscles. J Sport Rehabil. 2012;21(1):1-5.

15. Otman AS, Köse N. Tedavi Hareketlerinde Temel Değerlendirme Prensipleri. Ankara: Pelikan \& Tip Teknik Yayıncılık; 2016.

16. Cramer J, Quintero M, Rhinehart A, et al. Exploration of score agreement on a modified upper quarter Ybalance test kit as compared to the upper quarter Ybalance test. Int J Sports Phys Ther. 2017;12(1):117-24.

17. Cosio-Lima L, Knapik, JJ, Shumway R, et al. Associations between functional movement screening, the $\mathrm{Y}$ balance test, and injuries in coast guard training. Mil Med. 2016;181(7), 643-8.

18. Johansson FR, Skillgate E, Lapauw ML, et al. Measuring eccentric strength of the shoulder external rotators using a handheld dynamometer: reliability and validity. J Athl Train. 2015;50(7):719-25.

19. Borms D, Cools A. Upper-extremity functional performance tests: reference values for overhead athletes. Int J Sports Med. 2018;39(6):433-41.

20. Butler RJ, Myers HS, Black D, et al. Bilateral differences in the upper quarter function of high school aged baseball and softball players. Int J Sports Phys Ther. 2014;9(4): 518-24.

21. Bullock GS, Schmitt AC, Chasse PM, et al. The relationship between trunk rotation, upper quarter dynamic stability, and pitch velocity. J Strength Cond Res. 2018;32(1):261-6.

22. Butler R, Arms J, Reiman M, et al. Sex differences in dynamic closed kinetic chain upper quarter function in collegiate swimmers. J Athl Train. 2014;49(4):442-6.

23. Salo TD, Chaconas E. Y-balance test scores in recreational weightlifters: a randomized controlled trial. Int J Sports Phys Ther. 2017;12(2):199-205.

24. Harasin D, Dizdar D, Markovic G. High reliability of tests of maximum throwing performance. J Hum Mov Stud. 2006;51(1):63-76. 